\title{
Measuring Dynamic Return and Volatility Connectedness among Nigerian Financial Markets
}

\section{Elias A. Udeaja ${ }^{\dagger, \ddagger}$}

This study employs the connectedness measure of Diebold and Yilmaz $(2012,2014)$ to examine the intensity of connectedness among the Nigerian financial markets for the period January 2000 to December 2018. The study used all shares index, Treasury bill rate and Naira/USD official exchange rate to measure stock market, money market and exchange rate market, respectively. The study found connectedness among the Nigerian financial markets to be highly time-varying and appear to be higher during the period of high depreciation of the naira which coincides with the period of falling oil prices and domestic economic meltdown of 2014 and 2016, respectively. This shows that, relative to external shocks, connectedness among financial markets is likely to get amplified during the time of domestic turbulence. The paper, therefore recommends that policymakers should look inward whenever policy discuss revolves around the increasing integration of financial markets to save the economy from aggravation of contagion.

Keywords: Connectedness, Financial Market, Nigeria, Return, Spillover, Volatility

JEL Classification: C58; F36; G11; G12

DOI: $10.33429 /$ Cjas. $10219.6 / 6$

\subsection{Introduction}

It goes without saying that, the increasing integration of financial markets across the globe has further exacerbated the vulnerability of economies around the world, to systemic shocks either emanating domestically, from intra-financial markets connectedness or globally, from the perspective of

\footnotetext{
† The author is a staff of Research Department, Central Bank of Nigeria, Abuja. eaudeaja@cbn.gov.ng.

$\$$ The views expressed in this paper, are purely those of the author, and do not represent the views of the Central Bank of Nigeria.
} 
inter financial market connectedness. While acknowledging the potential of such integration to facilitate trade among nations, the risks and uncertainties associated with such connectedness remains a major source of concern. The likely implications of such linkages, particularly the domestic economy (i.e. intra financial markets connectedness) has farreaching implications for policymakers and investors in the market. In other words, the possibility of shocks to a asset spilling to another asset is likely to compound the already challenging task of asset pricing and portfolio diversification strategies.

Thus, it is crucial for investors and policymakers to understand the intensity of connectedness amongst the financial markets, notably stock market, money and foreign exchange markets. In the case of the former, understanding the dynamics of the interdependence of the markets matter for the effectiveness of their portfolio strategies. For policymakers, scrutinizing the channel of transmission among these markets will enable them identify the market that is more vulnerable to risks/uncertainties and enable them formulate appropriate policy choices to deal with it. Hence, any attempt to provide evidence-based information on the intensity of connectedness among financial markets cannot be overemphasized as it gives investors useful insight on how to diversify their portfolio investments to maximize returns.

Although, the question of financial markets connectedness is not new in finance literature, however, the level of connectedness in the global market and the accompanying risks became evident when almost all economies in the world were affected negatively by the global financial crisis (GFC). Thus, literature on the connectedness of financial markets has continued to gain importance during and aftermath of the 2007/2008 GFC. However, the majority of extant studies mainly focus on the interdependence of financial markets in the developed countries, for example, Andersen et, al. (2007) for the U.S., Germany and Britain, Hakim and McAleer (2009) for Australia and New Zealand, Diebold and Yilmaz (2012) for the U.S., Sensoy and Sobaci (2014) for Turkey, Liow (2015) for G7, and Kal et al. (2015) for Australia, United Kingdom, Canada and Japan.

Although, Nigeria is a small open economy, the fact that the economy is import dependent is an indication, that financial markets in the country are 
highly exposed to exogenous shocks, like the one from the 2007/2008 GFC. Consequently, any attempt to understand the dynamics of the connectedness among the country's financial markets is crucial to unraveling the hedging potential of these markets. Such hedging potential if adequately measured, is capable of providing diversification benefits to investors, particularly in turbulent periods such as the crash of international oil prices and the recent economic recession witnessed, in 2014 and 2016, respectively. There have been quite a number of studies on the connectedness of financial markets mostly from the cross border perspective. This has left the connectedness of domestic markets linkage largely unexplored. This therefore, is an important gap that this study is attempting to fill.

The contribution of this paper to extant literature, is in threefold. First, the study focuses on the connectedness of domestic market of emerging economy using Nigeria's financial market as a case study. Second, this study accounts for both returns and volatility spillovers among the three major financial markets in Nigeria (stock, money and foreign exchange markets). Third, this study uses the Diebold and Yilmaz (2012, 2014) [Henceforth; DY] spillovers indices to measure not only the intensity of connectedness among the investigated financial markets, but to also reflect the various cyclical events likely to influence the degree of return and shocks transmission across the three financial markets under consideration.

Using the connectedness measure developed by DY $(2012,2014)$, this study offers many exciting insights as potential guide to investors, policymakers as well as academics on the resilience and/or vulnerability of the Nigerian financial markets from the perspectives of internal intermarket shocks transmission.

In addition to the introduction section, the next section presents and reviews both theoretical framework and empirical literature. Section three explains the data, discusses the adopted methodology and also offers some preliminary analyses. The empirical findings are documented and analyzed in section four, while section five (5) concludes the paper and makes some policy recommendations. 


\subsection{Literature Review}

\subsection{Theoretical Framework}

There is no gainsaying that the Generalized Vector Autoregressive (VAR) method, developed by Koop, Pesaran and Potter (1996) and then Pesaran and Shin (1998) often referred as KPPS remain the basis of the various alternative methods often utilized for analyzing spillover in the literature (see Salisu et al., 2018). However, and partially due to its relative newness and robustness, the DY method has been widely accepted as the preferred measure of connectedness index. Unlike the conventional VAR, the DY which uses decomposition of forecast error variance from VAR is suitable for the evaluation of the degree of interdependence among countries, assets and markets across different regions and within a country. There are many spillovers that can be generated using DY method, namely; Total-Spillovers, Directional-Spillovers, and Net-Pairwise-Spillovers (see Salisu et al., 2018; Sobti, 2018).

\subsection{Empirical Literature}

While acknowledging the proliferation of literature on the connectedness of financial markets both from the perspectives of domestic and cross border analyses, the review of literature herein mainly consider studies based on DY connectedness measure. In their seminal paper, DY (2009) considered nineteen (19) global stock markets covering the period January, 1992 and November, 2007. The study finds that, contrary to return spillovers which display gently increasing trend without bursts, the volatility spillovers exhibit no trend but strong bursts. Following the DY (2009) approach, Yilmaz (2010) explores VAR of returns and rangebased volatility method to investigate contagion among East Asian stock markets. Findings reveals that returns spillovers exhibits increased contagion amongst the investigated market, while the volatility spillovers index exhibits significant bursts in the crisis period.

As a further build up to their 2009 seminal paper, DY (2012) studies four classes of assets namely; stocks, bonds, foreign exchange and commodities market with U.S. economy as the case study. Findings from the study provides significant evidence of volatility fluctuations in all the four markets, but provides limited evidence of cross market volatility transmission at least not until the advent of 2007-2008 GFC. According to the authors, the instance of increasing volatility spillovers coincides with the period of GFC with the direction of transmission mainly from the 
stock market to other markets. DY (2014), uses equity returns volatility data of U.S. financial firms to determine the intensity of connectedness amongst firms. The findings suggest that financial interdependences are crucial in the transmission of shocks across different economic entities. Compared to their findings from earlier studies, index of connectedness among international stocks is as high as $78 \%$.

Aside from DY, other studies have also explored the connectedness index. Tsai (2014) for example, adopted the approach of DY (2012) to estimate spillover indices for stock markets of five major advanced economies namely; US., U.K., Germany, Japan and France and the empirical findings indicate U.S. as the net transmitter of shocks to other markets. FernándezRodríguez et al. (2015) as well as Antonakis and Vergos (2013) also explore the VAR -based spillover index to analyze spillovers of volatility in EMU sovereign bond markets following DY (2012) approach. The studies in their respective finding show that shocks due to sovereign bond yield spread (BYS) tend to increase future BYS on the average. Also, Claeys and Vašíc ek (2014) uses the factor augmented variant of the VAR model in DY (2009) to measure the intensity and direction of connectedness among 16 European Union (EU) sovereign bond markets. Finding from the study suggests there is substantial spillover, especially between EMU countries, with Belgium, Italy and Spain being key markets during the financial crisis.

In their evaluation of the degree of connectedness among the financial and real sectors of some advanced economies with some selected African economies, Ogbuabor et al. (2016) using DY (2012) spillovers index measure shows that, compared to the pre-GFC, the GFC tends to intensify the connectedness of African economies with the global economy. Finding from the study particularly indicates U.S., Canada and EU as representative of the global economy that dominate equity markets in Africa, while the real sector of the Africa economy is dominated by China, India and Japan. Using the case of BRICS and three global bond market indices (represented by Japan, USA and European Monetary Union), Ahmad et al. (2018) finds that, Russia, followed by South Africa are the net transmitter of shocks compared to other BRICS member countries. The fact that the study reveals China and India as the countries with least degree of connectedness means that these two countries have the potential for hedging and diversification opportunities in BRICS. 
Salisu et al. (2018), considers six most traded currency pairs in the world in their analysis of return and volatility spillovers using DY (2012) approach. Essentially, the study computes total, directional and spillover indexes covering the period from January, 1999 to December, 2014. On the whole, the study find significant evidence of connectedness amongst the major traded currency pairs considered. However, the study also finds that while return spillovers exhibit mild trends and bursts, the volatility spillovers on the other hand only exhibit significant burst but no trends. Using the case of India, Sobti (2018) also adopts DY (2014) to measure the intensity of connectedness among the five key financial markets in India namely, bond market, stock market, money market, foreign exchange and commodity markets. Findings from the study indicates foreign exchange and stock markets as the largest transmitter of shocks to return, while commodity market emerges as the net transmitter of volatility to other asset markets.

\subsection{Data and Methodology \\ 3.1 Data}

The study utilizes monthly series over a fifteen-year period spanning January, 2000 to December, 2018. The sample period was carefully chosen to cover notable episodes of both global and internal economic evolution and/or financial crisis such as; the period before and after the 2007 GFC, the 2014 oil price meltdown and the domestic economic recession in 2016. Salisu et al. (2019) also covered similar sample period in their analysis of return, shock and volatility spillovers between Nigerian financial market. The Nigerian All Share Index (ASI) is taken as a proxy for stock market, while three (3) month Treasury Bill Rate (TBR) and Naira/USD exchange rate proxies for money and forex markets, respectively. The data are mainly sourced from the online database of the Central Bank of Nigeria (CBN).

\subsection{The Methodology: The Diebold -Yilmaz (DY) Approach}

The underlying framework for the DY spillover indexes is the generalized vector autoregressive (VAR) model of KPPS. Essentially, we followed the DY $(2012,2014)$ approach to set up a directional spillover indexes in a generalized VAR framework that is invariant to variable ordering (i.e. it eliminates the possible dependence of the results on ordering). Setting up the spillover indexes starting from equation (1), a covariance stationary $N$-variable $\operatorname{VAR}(p)$ was considered. 


$$
X_{t}=\Phi_{1} X_{t-1}+\cdots+\Phi_{p} X_{t-p}+\varepsilon_{t}
$$

where $X_{t}=\left(X_{1 t}, X_{2 t}, \ldots, X_{N t}\right)$ is an $N \times 1$ vector of return/volatility series, while $\Phi$ denotes $N \times N$ matrix of parameters. Equation (1) can be further re-specified in a more compact form as follows:

$$
x_{t}=\sum_{i=1}^{p} \Phi_{i} x_{t-1}+\varepsilon_{t} ; \quad \varepsilon \sim(0, \Sigma)
$$

where $\varepsilon$ is a vector of independently and identically distributed disturbances. Re-specifying the VAR process in equation (2) as a moving average (MA) will yield the following:

$$
x_{t}=\sum_{i=0}^{\infty} A_{i} \varepsilon_{t-i}
$$

where $A_{i}$ is said to obey the recursion $A_{i}=\Phi_{1} A_{i-1}+\Phi_{2} A_{i-2}+\cdots+\Phi_{p} A_{i-p}$. $A_{0}$ is an $N \times N$ identical matrix and $A_{i}=0$ for $i<0$. The MA process in equation (3) forms the basis for the derivation of variance decompositions and which in turn permits portioning of the forecast error variance of individual variables. Thus, the process of providing the representations for the various indexes started with the H-step ahead forecast error variance decomposition using the KPPS generalized VAR method.

$$
\theta_{j j}^{g}(H)=\frac{\sigma_{J}^{-1} \sum_{h-0}^{H-1}\left(e_{i}^{\prime} A_{h} \Sigma e_{j}\right)^{2}}{\sum_{h-0}^{H-1}\left(e_{i}^{\prime} A_{h} \Sigma A_{h}{ }^{\prime} e_{i}\right)},
$$

where $\Sigma$ is the variance matrix for the error vector $\varepsilon$, while $\sigma_{j j}$ denotes the conventional process of the deviance of the error-term for the $j$ th element. The term $e_{i}$ is the choice error such that the $i$ th element equal one but zero if otherwise. It is however, noteworthy that the sum of the contributions to the variance of the forecast error is not necessary equal to one. Hence, the normalized KPPS H-step-ahead forecast error variance decomposition is as below:

$$
\tilde{\theta}_{i j}^{g}(H)=\frac{\theta_{i j}^{g}(H)}{\sum_{J=1}^{N} \theta_{i j}^{g}(H)}
$$

where $\sum_{J=1}^{N} \tilde{\theta}_{i j}^{g}(H)=1$ and $\sum_{i, j=1}^{N} \tilde{\theta}_{i j}^{g}(H)=N$ by construction. 
At this juncture, we can now calculate total connectedness measure or the total spillover index as follows:

$$
S^{g}(H)=\frac{\sum_{\substack{i, j=1 \\ t \neq j}}^{N} \tilde{\theta}_{i j}^{g}(H)}{\sum_{i, j=1}^{N} \tilde{\theta}_{i j}^{g}(H)} \times 100=\frac{\sum_{\substack{i, j=1 \\ t \neq j}}^{N} \tilde{\theta}_{i j}^{g}(H)}{N} \times 100
$$

Although, the parameters in equation (6) remain as earlier defined, the essence of the equation is to determine the degree of the transmission of shocks across the three financial markets under consideration. In the context of this study, the total spillover index captures the contribution of spillover and volatility shocks across the three main Nigerian financial markets under consideration namely, stock market, money market and forex market to the total forecast error variance.

It is also possible to assess quantitatively, the direction of spillovers across these financial markets. Such directional spillovers are usually captured as: Directional Spillover To (measuring degree of spillovers of return or volatility from say market $i$ and Directional Spillover From. Starting with the latter, the concern is in respect to return and/or volatility transmission from say market $i$ to market $j$ implying other markets). The concern with the former is to determine the degree of spillovers of return and volatility from other markets to market $i$. Mathematically, the directional volatility spillovers received by market $i$ from all other markets $j$ is measured as:

$$
S_{i *}^{g}(H)=\frac{\sum_{j=1}^{N} \widetilde{\theta}_{i j}^{g}(H)}{\sum_{j=1}^{N} \widetilde{\theta}_{i j}^{g}(H)} * 100=\frac{\sum_{j=1}^{N} \widetilde{\theta}_{i j}^{g}(H)}{N} * 100
$$

Similarly, the directional volatility spillovers from market $i$, to all other markets $j$, is measured as:

$$
S_{* i}^{g}(H)=\frac{\sum_{\substack{j=1 \\ j \neq i} \widetilde{\theta}_{j i}^{g}(H)}^{g}\left(\widetilde{\theta}_{j i}^{g}(H)\right.}{\sum_{j=1}^{N} \widetilde{\theta}_{j i}^{g}} * 100=\frac{\sum_{\substack{j \neq 1 \\ j \neq i}}^{N} \widetilde{\theta}_{i j}^{g}(H)}{N} * 100
$$

From equations (7) and (8) the index for net spillovers can therefore, be represented as:

$$
S_{i}^{g}(H)=S_{* i}^{g}(H)-S_{i *}^{g}(H)
$$

In addition to the summary of information provided by the net connectedness measure in equation (9), one may also be interested in 
calculating the net pairwise volatility connectedness measure as algebraically shown in equation (10).

$$
S_{i j}^{g}(H)=\left[\frac{\widetilde{\theta}_{i j}^{g}(H)}{\sum_{k=1}^{N} \widetilde{\theta}_{i k}^{g}(H)}-\frac{\widetilde{\theta}_{j i}^{g}(H)}{\sum_{k=1}^{N} \widetilde{\theta}_{j k}^{g}(H)}\right] * 100
$$

Equation (10) is meant to reflect the net volatility spillover measure as the difference between the total volatility shocks transmitted from market $i$ to market $j$ and vice-versa.

Finally, return for the respective market is calculated as below using logarithm as a continuous compounded monthly return.

$$
R_{i, t}=100 * \log \left(P_{t} / P_{t-1}\right)
$$

\subsection{Analysis and Presentation of Results \\ 4.1 Preliminary Analysis}

Presented in Table 1, are the descriptive statistics of all the series, in their return and volatility forms. Inference from the mean statistic shows that all the three markets exhibit positive returns, with the money market yielding the highest returns. Considering the standard deviation statistic, as well as, the mean value from the perspective of volatility series, the stock market appears to be the riskiest of all the three markets. Equally notable is the profound evidence of non-zero skewness and fatter tails by the kurtosis statistic, while the Jarque-Bera (JB) statistic that takes into consideration information from skewness and kurtosis to test for normality shows that the series are not normally distributed.

Table 1: Descriptive Statistics of the three Financial Markets

\begin{tabular}{lcccccc} 
& \multicolumn{3}{c}{ Return summary statistics } & \multicolumn{3}{c}{ Volatility summary statistics } \\
\cline { 2 - 7 } Statistics & ASI & NTBs & EXR & ASI & NTBs & EXR \\
\hline Mean & 0.5611 & 2.4360 & 0.4994 & 0.6250 & 0.0606 & 0.0006 \\
Std. Dev. & 39.6210 & 0.5214 & 2.4741 & 5.3004 & 0.1725 & 0.0026 \\
Skewness & -11.7536 & -0.6300 & 6.1081 & 12.2537 & 5.8168 & 10.6339 \\
Kurtosis & 164.8437 & 3.7395 & 48.8852 & 162.3283 & 45.0121 & 127.2431 \\
\multirow{2}{*}{ JB statistic } & 12.3407 & 40.2028 & 115.7077 & 245785.3 & 17974.1 & 150280.3 \\
& $(0.0020)$ & $(0.0000)$ & $(0.0000)$ & $(0.0000)$ & $(0.0000)$ & $(0.0000)$ \\
\hline
\end{tabular}

We further subject each of the series to unit root tests which are a precondition for a meaningful time series analysis. We consider both the 
Augmented Dickey-Fuller (ADF) test and its modified version namely, Dickey-Fuller GLS (DF-GLS) test. The unit root test is performed on the return series for each market. Table 2 shows that the null hypothesis of unit root can be rejected in all the three markets thus reaffirming the appropriateness of VAR as the underlying framework for the DY spillover indexes.

Table 2: Unit root test result

\begin{tabular}{lcccccc}
\hline & \multicolumn{3}{c}{ ADF test } & \multicolumn{3}{c}{ DF-GLS test } \\
\cline { 2 - 7 } & \multicolumn{1}{c}{ Level } & $\begin{array}{c}\text { First } \\
\text { Difference }\end{array}$ & $\mathrm{I}(\mathrm{d})$ & Level & $\begin{array}{c}\text { First } \\
\text { Difference }\end{array}$ & $\mathrm{I}(\mathrm{d})$ \\
\hline Stock & $-14.3750^{* * *}$ & - & $\mathrm{I}(0)$ & $-14.3853^{* * *}$ & - & $\mathrm{I}(0)$ \\
Money & $-11.6457^{* * *}$ & - & $\mathrm{I}(0)$ & $-11.6641^{* * *}$ & - & $\mathrm{I}(0)$ \\
FOREX & $-7.0684^{* * *}$ & - & $\mathrm{I}(0)$ & $-6.8916^{* * *}$ & - & $\mathrm{I}(0)$ \\
\hline
\end{tabular}

Note: The exogenous lags are selected based on Schwarz info criteria while **** represents $5 \%$ level of significance.

\subsection{Empirical Results}

For a meaningful evaluation of the transmission mechanism amongst the three financial markets under consideration, the empirical analysis carried out, involved the correlation of the $\log$ returns of the markets. The importance of the correlation analysis can be argued from the view point of portfolio management. For instance, when financial assets in one market move in tandem with assets in other markets, such co-movements is likely to exacerbate risk associated with the portfolio as well as systematic risk within a country. However, where an asset is least affected by activities in the other markets, the reverse is likely to be the case; this is likely to reduce average risk of portfolio.

Table 3: Unconditional correlation matrix

\begin{tabular}{cccc} 
& Stock-Market & Money-Market & FOREX-Market \\
\hline Stock-Market & 1 & & \\
Money-Market & $-0.0366^{* *}$ & 1 & \\
FOREX-Market & 0.0677 & 0.0471 & 1 \\
\hline
\end{tabular}

Note: *** represents significance at $5 \%$ significance level

Presented in Table 3 is the result of the unconditional correlations performed on the log returns of stock market, money market and FOREX market. A cursory look at the table shows that the stock market on the one hand exhibits negative correlation with money market, but positive 
correlation with FOREX market on the other hand. However, the correlation is only statistically significant in the case of stock and money markets relationship. What this portends, is that money market and not FOREX market is statistically viable as a good hedge to stock market.

\subsection{Static (Full -sample, unconditional analysis)}

Prior to evaluating the degree of connected among the three financial markets under consideration, presented in Table 4 is a schematic of connectedness matrix and the essence to aid our illustration of the magnitude of volatility in $i^{\text {th }}$ market attributable to shocks due to market $j^{\text {th }}$ market and vice-versa.

Table 4: Schematic connectedness table

\begin{tabular}{|c|c|c|c|c|c|}
\hline & $x_{1}$ & $x_{2}$ & $\cdots$ & $x_{N}$ & $\begin{array}{c}\text { Connectedness from } \\
\text { Others }\end{array}$ \\
\hline$x_{1}$ & $d_{11}^{H}$ & $d_{21}^{H}$ & $\ldots$ & $d_{1 N}^{H}$ & $\sum_{j=1}^{N} d_{1 j}^{H}, j \neq 1$ \\
\hline$x_{2}$ & $d_{12}^{H}$ & $d_{22}^{H}$ & $\ldots$ & $d_{2 N}^{H}$ & $\sum_{j=1}^{N} d_{2 j}^{H}, j \neq 2$ \\
\hline . & . & . & . & . & . \\
\hline . & . & . & . & . & . \\
\hline$\cdot$ & . & $\cdot$ & . & . & 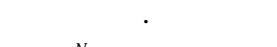 \\
\hline$x_{N}$ & $d_{N 1}^{H}$ & $d_{N 2}^{H}$ & $\ldots$ & $d_{N N}^{H}$ & $\sum_{j=1}^{N} d_{N j}^{H}, j \neq N$ \\
\hline $\begin{array}{l}\text { Connectedness } \\
\text { to Others }\end{array}$ & $\sum_{\substack{i=1 \\
i \neq 1}}^{N} d_{i 1}^{H}$ & $\sum_{\substack{i=1 \\
i \neq 2}}^{N} d_{i 2}^{H}$ & $\cdots$ & $\begin{array}{l}\sum_{i=1}^{N} d_{i N}^{H} \\
i \neq N\end{array}$ & $\begin{array}{c}\frac{1}{N} \sum_{i, j=1}^{N} d_{i N}^{H} \\
i \neq N\end{array}$ \\
\hline
\end{tabular}

Source: DY (2014)

In line with the connectedness matrix in Table 4, the spillover tables (see Tables $5 \mathrm{a}$ and $5 \mathrm{~b}$ ), denoting the degree of return and volatility connectedness among the three Nigerian financial markets considered are produced. The degree of connectedness among the markets is calculated via the $i j$ entry known as spillover table. The spillover tables help summarize the contribution to volatility in $i^{\text {th }}$ market that is due to shocks to market $j$. Represented in the diagonal elements of the spillover tables include shock estimates due to own innovations. Regarding the offdiagonal row elements, the spillovers tables estimate the effects of spillovers of return and volatility received by market $i$ from shocks due to all other markets (i.e. Directional spillovers from other market: column). 
Consequently, the on the off-diagonal elements from the column perspective gives estimate on the spillover effect from market $i$ to all other markets for instance directional spillovers to other markets (row). By subtracting the 'directional spillovers from', from the 'directional spillovers to', we arrived at the net spillover effects from market $i$ to all other markets. In a similar development, we divide the grand sum of the off-diagonal elements by the grand sum of all elements in the table to arrive at the total spillover index expressed in percentage points.

Table 5a: Spillover table for the full connectedness of the three Financial Markets: Return spillover table

\begin{tabular}{lcccc} 
& Stock & Money & FOREX & $\begin{array}{c}\text { Directional Spillovers } \\
\text { from other Markets }\end{array}$ \\
\hline Stock & 97.6 & 1.4 & 1 & 2.4 \\
Money & 0.5 & 99.2 & 0.3 & 0.8 \\
$\begin{array}{l}\text { FOREX } \\
\text { Directional Spillovers }\end{array}$ & 0.2 & 0.3 & 99.5 & 0.5 \\
to other Markets & 0.7 & 1.7 & 1.3 & 3.7 \\
& & & & \\
Directional including own & 98.3 & 100.9 & 100.8 & \\
Net Spillovers & 95.9 & 100.1 & 100.3 & $(3.70 / 300) * 100=1.23 \%$ \\
& & & & \\
\end{tabular}

Table 5b: Spillover table for the full connectedness of the three Financial Markets: Volatility spillover table

\begin{tabular}{lcccc}
\hline & Stock & Money & FOREX & $\begin{array}{c}\text { Directional Spillovers } \\
\text { from other Markets }\end{array}$ \\
\hline Stock & 100.00 & 0.00 & 0.00 & 0.00 \\
Money & 0.10 & 98.50 & 1.40 & 1.50 \\
FOREX & 7.30 & 0.20 & 92.50 & 7.50 \\
$\begin{array}{l}\text { Directional Spillovers } \\
\text { to other Markets }\end{array}$ & 7.40 & 0.20 & 1.40 & 9.00 \\
$\begin{array}{l}\text { Directional including own } \\
\text { Net Spillovers }\end{array}$ & 107.40 & 98.70 & 93.90 & Total Spillover Index \\
\hline
\end{tabular}

Note: The $i j$ th entry gives the $i j$ th pairwise directional connectedness.

Starting with return connectedness, the empirical estimates in Table 5a with the total spillover index at $1.23 \%$ is an indication of low level of 
return connectedness among stock, money and foreign exchange markets in Nigeria. For instance, the examination of the gross directional return spillover suggests that only $2.4 \%$ of the variations in stock returns might be due to spillover of shocks from other markets. For money market and foreign exchange market, the magnitude of spillover effect from other markets is less than $1 \%$, respectively. However, the net spillovers reveal FOREX market with $100.3 \%$ net spillovers as highest net transmitter of shocks followed closely by money market with $100.1 \%$. With respect to volatility spillover, the FOREX market appears the least transmitter of shocks and yet double as the net receiver of volatility transmission from other markets. This however, is expected of a country practicing managed float exchange rate regime. Therefore, the overall connectedness among the Nigerian markets appears to be more pronounced for spillovers due to volatility in these markets relative to connectedness due to return spillovers.

\subsection{Rolling Sample Analyses}

\subsubsection{Conditioning and dynamic I (Total spillover plots)}

The spillovers table as represented in Tables $5 \mathrm{a}$ and $5 \mathrm{~b}$, provides us with an overview for the "average" spillover effects over the full sample. Diebold and Yilmaz (2012) however, opined that when tabulated, the spillover effects or estimates may not reflect adequately the significance of some notable episodes of financial crisis or economic evolution. To this end, we proposed a rolling sample framework using 100-month sub sample rolling window in order to account for some of these financial evolution and crisis. This is consistent with our selected sample period covering the period before and aftermath of financial crisis, the 2014 oil price meltdown and the economic recession in 2016, the time depended return spillover index in Figure 1, revealed that many changes took place during these periods. Precisely, the total return spillover plot mostly fluctuates between $5 \%$ and $25 \%$ in the post financial crisis period and between 5\% and 10\% during the period of falling oil prices in 2014 . 


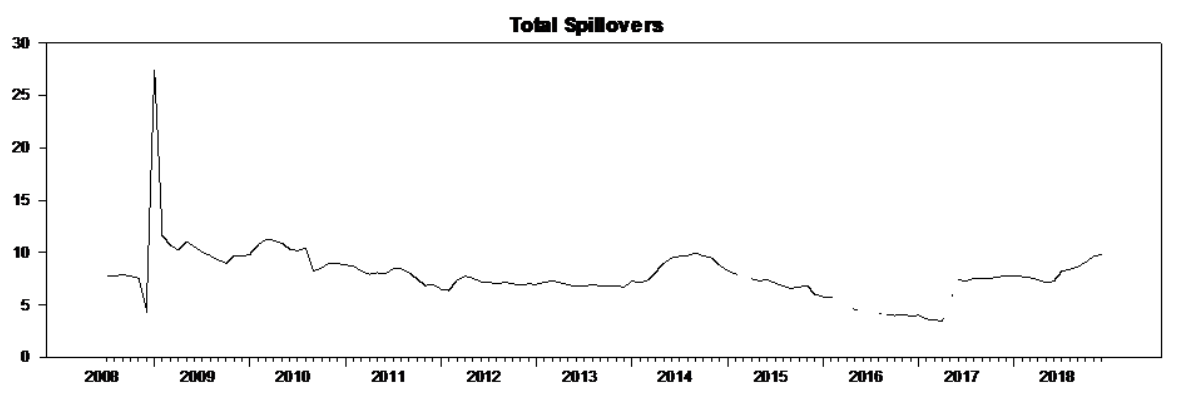

Figure 1: The Full Sample Return Spillover

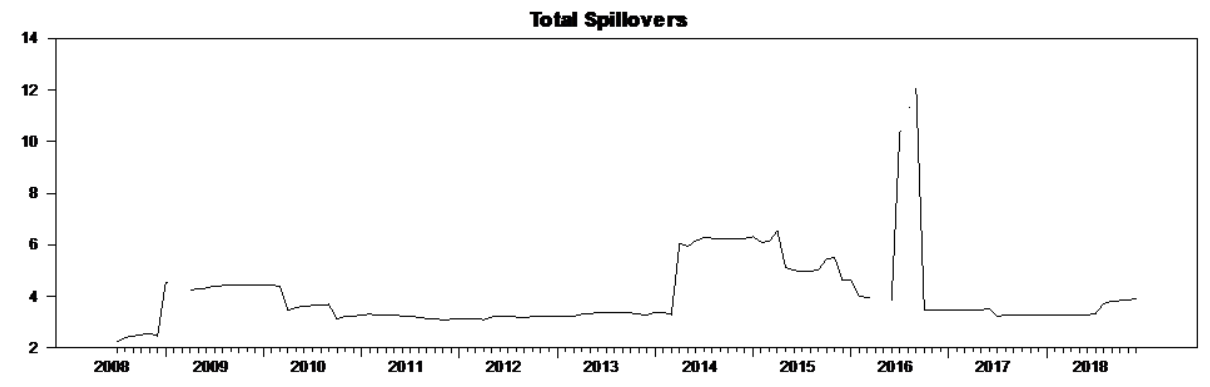

Figure 2: The Full Sample Volatility Spillover

We also abserved a number of spikes in the total volatility spillover plot in Figure 2 and the most notable of them, coincides with the period of economic recession in 2016 where the volatility spillover appears to be at its peak. A synopsis of this period shows that after sustaining an impressive decades of economic growth, the advent of economic recession saw Nigeria breaking a number of downside records prompting a downward pressure on external reserves and consequently foreign exchange scarcity. This in turn resulted in a drastic depreciation of the Naira with the Dollar at the official exchange rate window rising from $\$ 168 /$ US\$ recorded in January 2015 to $\$ 306.4 /$ US\$ as at March 2017.

Similarly, quite a number of extant studies have reported significant evidence of cross market volatility transmission during or in the aftermath of a turbulent econiomic period (for example, DY (2012) and Ogbuabor et al. (2016)).

\subsubsection{Conditioning and Dynamic II (gross directionl spillover plots)}

So far we have only accounted for the total spillover plots as it affects the returns and volatility index. Thus, Figure 3 shows the dynamic ways of representing the row and column estimates in Table 5, precisely in a manner that is parallel to the earlier discussion on total spillover plots. 
Directional spillover plots provide information on how spillover is being trasmitted from one market to others and from other markets to a specific maket. The information is contained in the "Directional TO others" (row) and the "Direction FROM others".
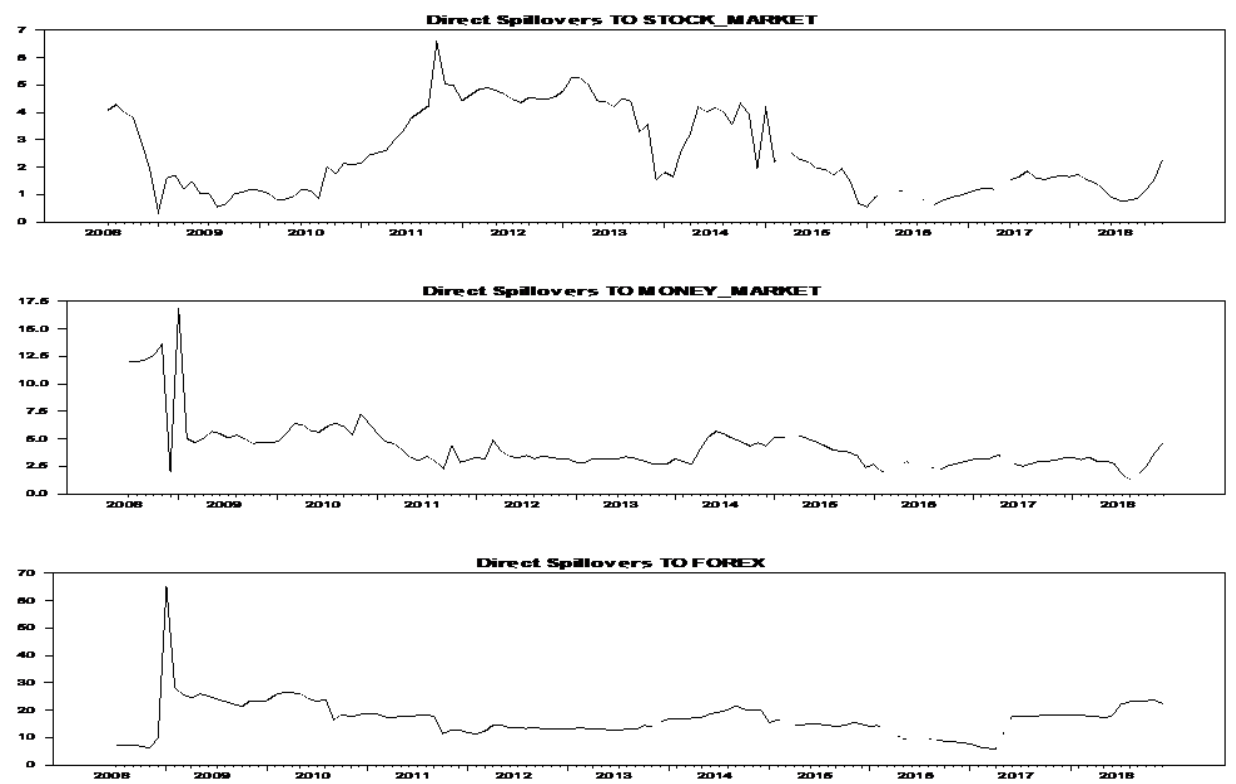

Figure 3: Gross Return Spillover Plots (Directional Spillovers from other Markets)
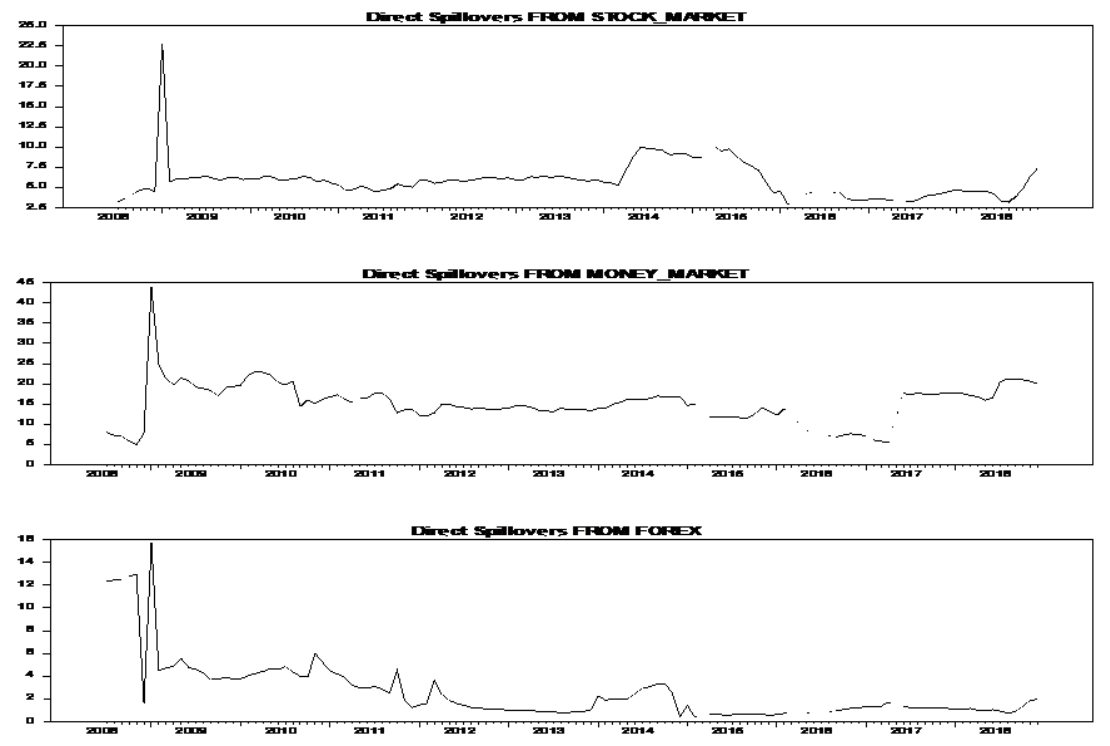

Figure 4: Gross Return Spillover Plot (Directional Spillovers to other Markets) 
In Figure 3, are the directional return spillovers to each of the financial market from others (corresponding to the "directional spillovers from others" in Table 5. Among the three markets, the return spillover from other market to foreign exchange market seems generally higher than that of other market irrespective of the period. In Figure 4, however, the directional return spillover from money market to others is the highest even in the post financial crisis period, where both the stock and FOREX markets appear to have recorded their maximum directional return spillover from. Consequently, Figures 5 and 6; present the directional volatility spillovers from the other markets to each of the three financial markets (Figure 6), as well as, from each of the market to others (Figure 7). As for directional spillovers from others, the maximum volatility spillover to each of the market is observed during the period of the domestic economic meltdown. On the whole, the FOREX market which is both the least transmitter of shocks as well the net receiver of volatility transmission from other markets appears to be the most vulnerable of all the three financial markets under consideration. That said, spillover from money market to other markets remains the highest even in the case of volatility (see Figure 6).
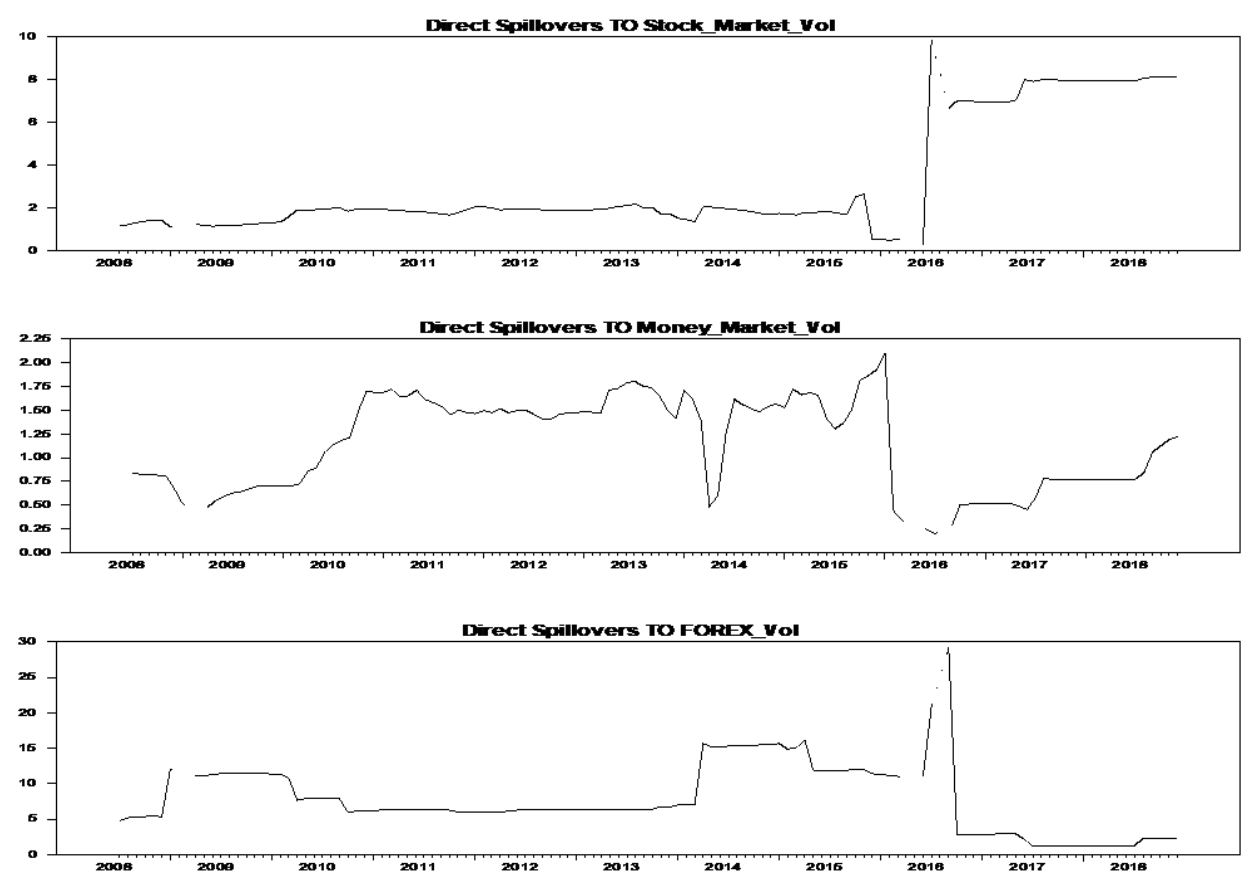

Figure 5: Gross Volatility Spillover Plots (Directional Spillovers from other Markets) 

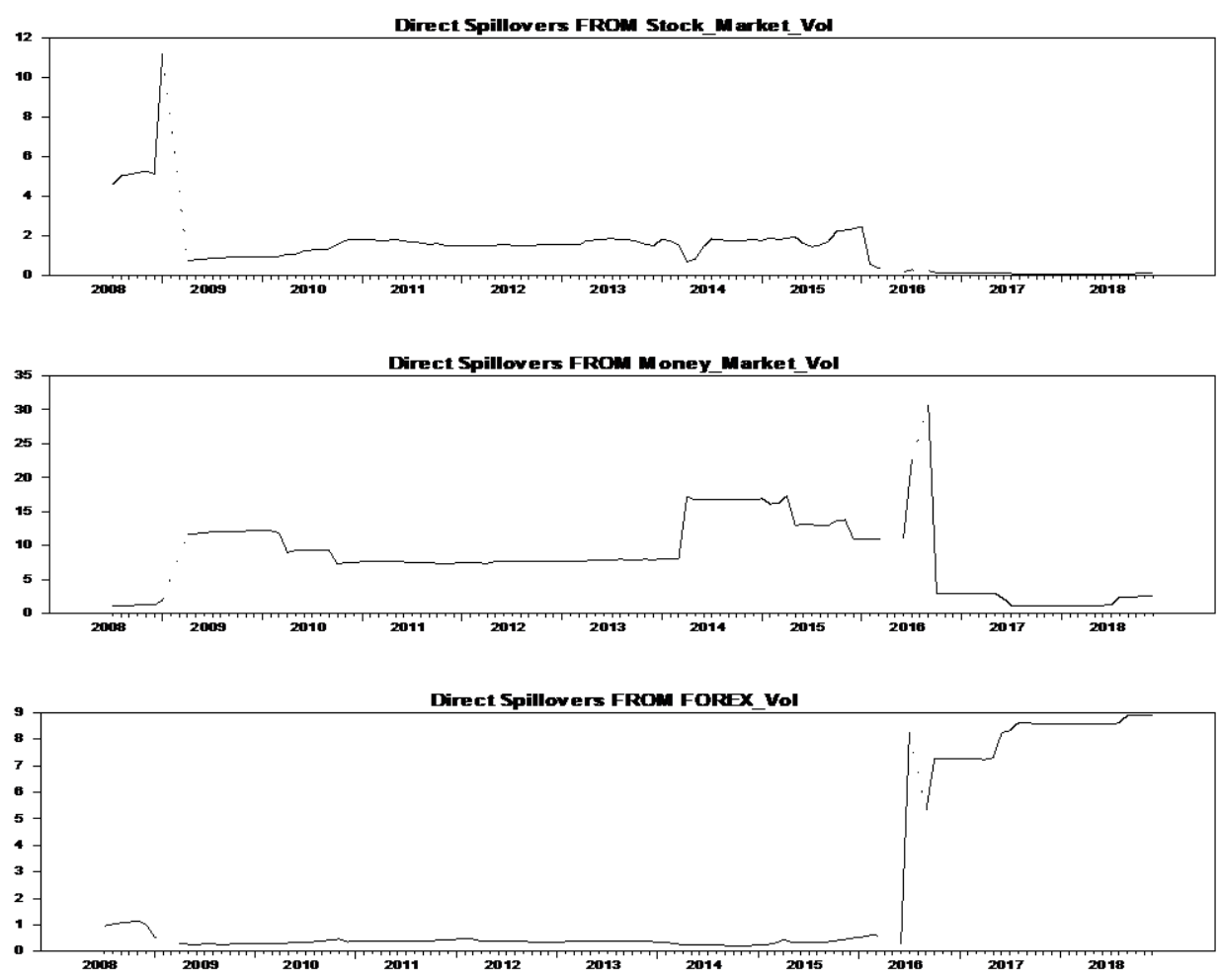

Figure 6: Gross Volatility Spillover Plots (Directional Spillovers to other)

\subsubsection{Conditioning and Dynamic III (net directionl spillover plots)}

Consideration must be given to the net directional spillover effects among the three financial markets. The essence of this is to enable the examination of the net transmitters and recievers of spillovers, in order to identify the main contributors to total spillovers. Figures 7 and 8 presents the net return and volatility spillovers for the three financial markets, which is the difference between the "Contribution from" column sum and the "Contribution to" row sum. 

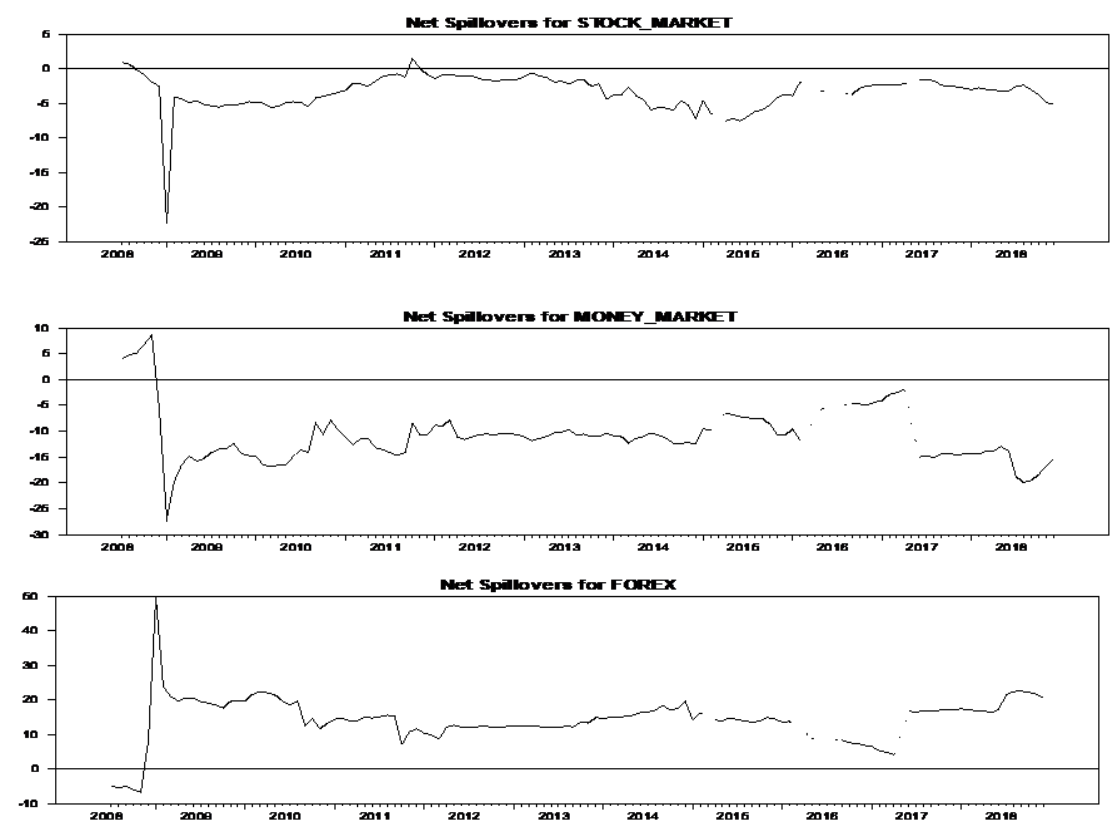

Figure 7: Net Return Spillover Plot for the three Financial Markets
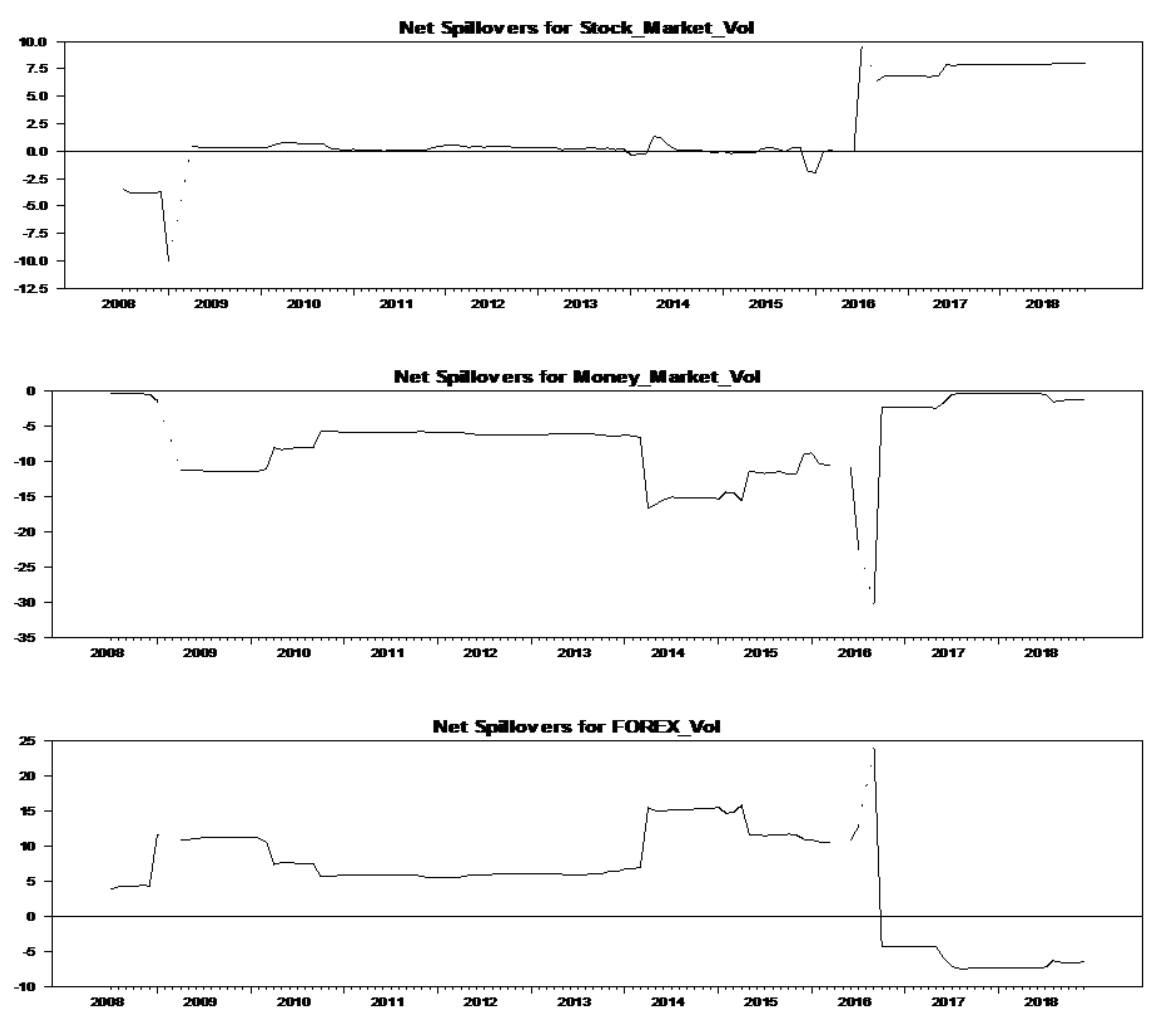

Figure 8: Net Volatility Spillover Plots for the three Financial Markets 
The net directional spillover plots in Figures 7 and 8 are calculated with positive and/or negative values for both returns and volatilities, respectively. The plots indicate that shocks due to market $i$ spreads (receives) to (from) other markets. Figure 7 revealed the FOREX market as relatively the net transmitter of returns spillovers and the reverse seems to be the case for stock and money markets. Furthermore, both stock and money markets only emerge net transmitters of return spillover in the period before and the immediate aftermath of 2007/2008 GFC. With respect to the net volatility spillover plots in Figure 8, it is stock and FOREX markets that appear to be the net transmitter of volatility in the three Nigerian financial markets. An interesting observation from Figure 8 , is the fact that the transmission of volatilities is in opposite direction between stock market and FOREX market especially during the period of economic recession in 2016 through to 2018.

\subsubsection{Net pairwise spillover analysis}

Empirical estimates are provided in respect of the net pairwise spillovers for the three markets. The net pairwise returns and volatility plots in Figures 9 and 10 were calculated with positive (negative) values implying that market $i$ transmits (receives) spillovers to (from) market $j$. The net return pairwise spillovers plots for all the three market in Figure 9, reveals the foreign exchange market as the net transmitters of return spillover toward stock market in most of the sample period. The net spillover pairwise between money market and stock market indicate the latter as net transmitters of return spillover. Spillover pairwise for money market and FOREX market reveal FOREX as the net transmitters of returns, but mainly in the turbulent period such as the early signs of GFC in 2007, as well as, in the post crisis period. Regarding net pairwise volatility spillovers as depicted in Figure 10, the picture seems clearer wit stock market being a net volatility spillover receiver from both the money market and foreign exchange market. For money market and foreign exchange market, the pattern of net volatility spillover revealed FOREX market as the net transmitters of volatility spillover at least not until the advent of economic recession in 2016. 

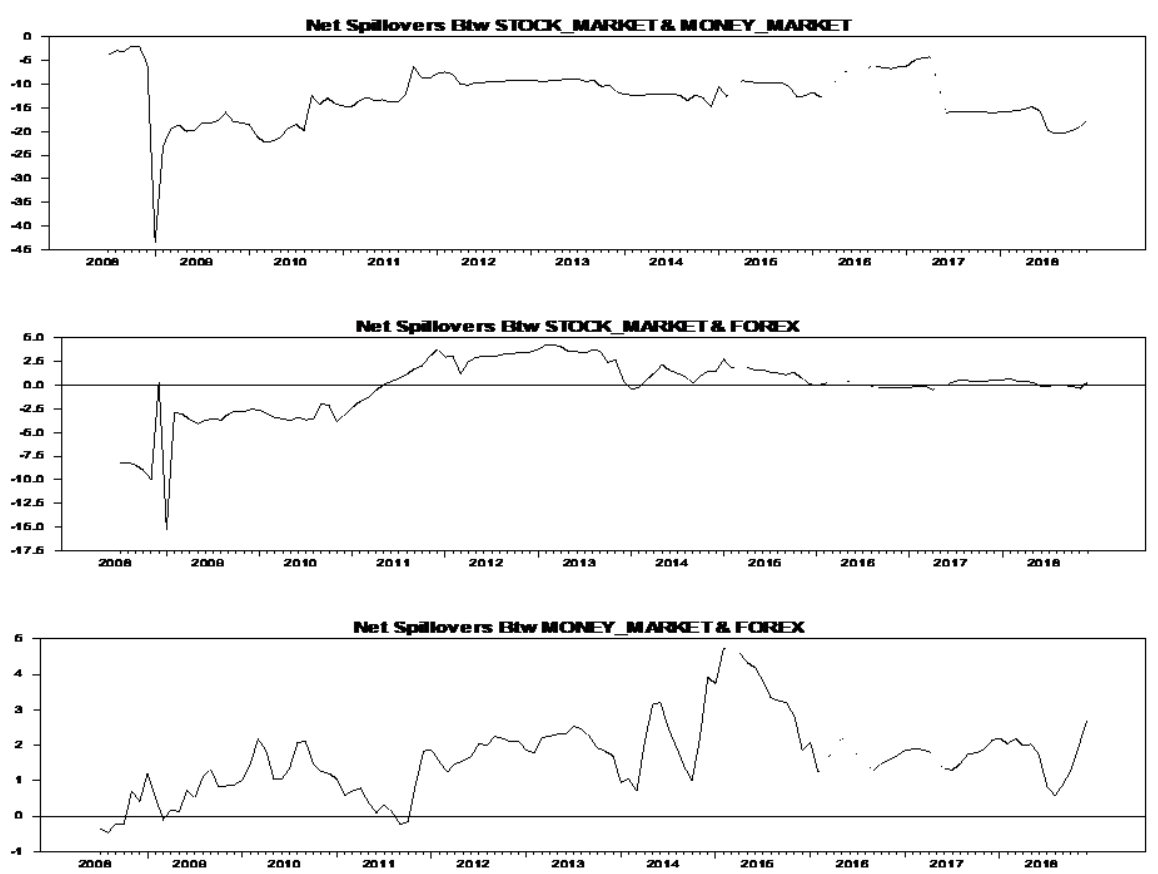

Figure 9: Net Pairwise Return Spillovers
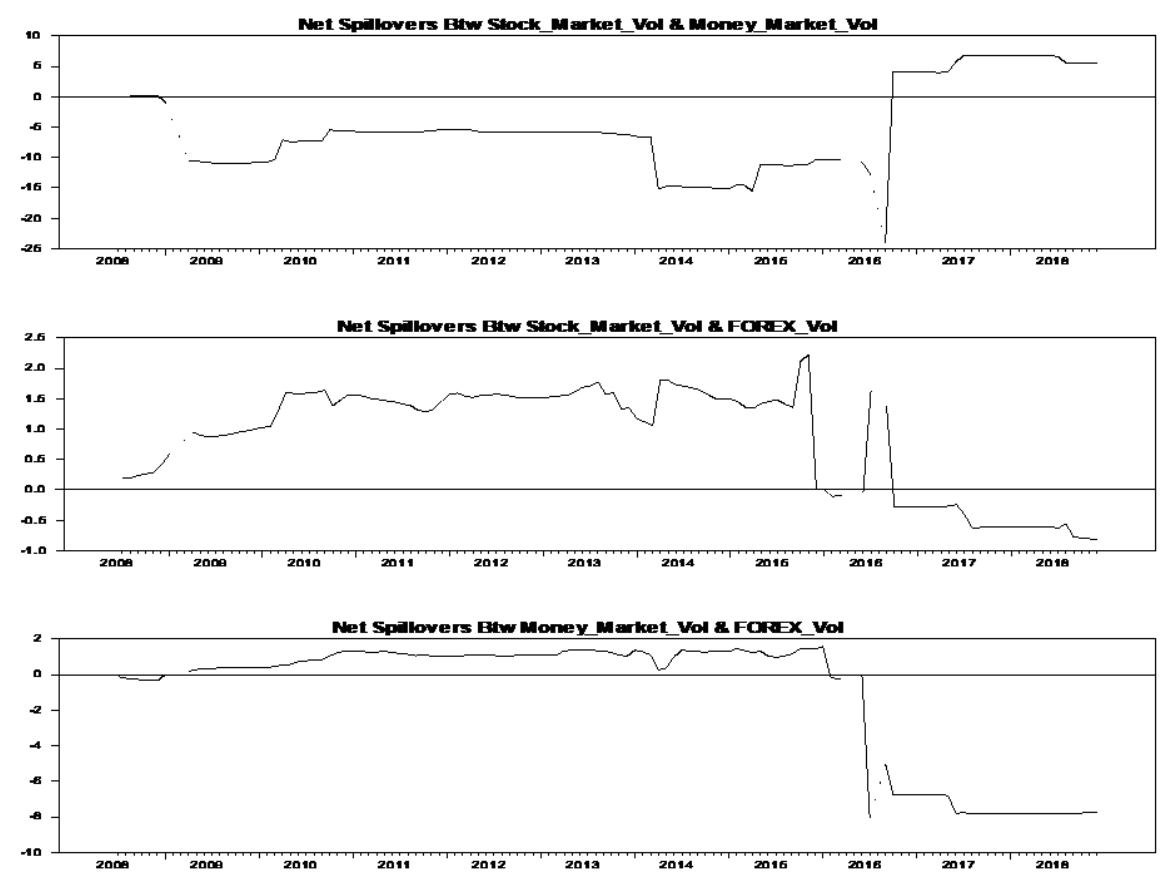

Figure 10: Net Pairwise Volatility Spillovers 


\subsection{Conclusion and Policy Recommendations}

\subsection{Conclusion}

Motivated by the growing integration among financial markets and the consequences of such connectedness for portfolio allocation and asset pricing, this paper evaluated and measured the intensity of connectedness among financial markets in Nigeria. Essentially, literature on the underlying source of risk exposure has increasingly shifted from the external perspective to internal ones. Exploring the DY measure of connectedness index, we observed that for an emerging economy such as Nigeria, its financial markets are likely to be more responsive to domestic economic turbulence than they would, to external shocks. Also, our finding of the stock market as the highest transmitter of volatility spillovers when compared to FOREX and money markets conform to the portfolio balance model, where it is revealed that an increase in domestic stock prices will increase investors' demand for domestic assets, by selling foreign assets in order to have more domestic currency which is likely to increase interest rates and currency appreciation. In this regard, the Central Bank of Nigeria (CBN) being the manager of Nigerian's economy from the perspective of financial stability would be expected to manage the volatilities of stock and FOREX markets. The findings of negative correlation between stock market and money market also matters as it affects investors' abilities to predict the behaviour of one market by having the information of other markets.

\subsection{Policy Recommendations}

It is recommended that policymakers should look both inward and outward whenever policy discuss revolve around the increasing integration of financial markets in order to save the economy from aggravation of contagion. This recommendation is in line with our findings, coupled with the structure of the Nigerian economy and its high reliance on oil. Thus, in its pursuit of price and exchange rate stability CBN needs to capture not only the inherent contagions associated with the internal connectedness of the country's financial markets, but also their vulnerability to external shocks. 


\section{References}

Ahmad, W., Mishra, A. V., \& Daly, K. J. (2018). Financial connectedness of BRICS and global sovereign bond markets. Emerging Markets Review, 37, 1-16. https://doi.org/10.1016/j.ememar.2018.02.006

Andersen T.G, Bollerslev T, Diebold, F.X., \& Vega, C. (2007). Real-time price discovery in global stock, bond and foreign exchange markets. Journal of International Economics, 73, 251-277.

Antonakakis, N., \& Vergos, K. (2013). Sovereign bond yield spillovers in the Euro zone during the financial and debt crisis. Journal of International Financial Markets, Institutions and Money, 26, 258272.

Claeys P., \& Vašicek, B. (2014). Measuring bilateral spillover and testing contagion on sovereign bond markets in Europe. Journal of Banking and Finance, 46, 151-165.

Diebold, F.X., \& Yilmaz, K. (2014). On the network topology of variance decompositions: Measuring the connectedness of financial firms. Journal of Econometrics, 182, 119-134.

Diebold, F.X., \& Yilmaz, K. (2012). Better to give than to receive: Predictive directional measurement of volatility spillovers. International Journal of Forecasting, 23, 57-66.

Fernández-Rodríguez, F., Gómez-Puig, M., \& Sosvilla-Rivero, S. (2015). Volatility spillovers in EMU sovereign bond markets. International Review of Economics \& Finance, 39, 337352.

Hakim, A., \& McAleer, M. (2009). Forecasting conditional correlations in stock, bond and foreign exchange markets. Mathematics and Computers in Simulation, 79(9), 2830-2846.

Kal, S. H., Arslaner, F., \& Arslaner, N. (2015). The dynamic relationship between stock, bond and foreign exchange markets. Economic Systems, 39(4), 592-607. 
Koop, G., Pesaran, M. H., \& Potter, S. M. (1996). Impulse response analysis in nonlinear multivariate models. Journal of Econometrics, 74(1), 119-147.

Liow, K.H. (2015). Volatility spillover dynamics and relationship across G7 financial markets. North American Journal of Economics and Finance, 33, 328-365.

Ogbuabor, J.E., Orji, A., Aneke, G.C., \& Erdene-Urnukh, O. (2016). Measuring the real and financial connectedness of selected African economies with the global economy. South African Journal of Economics, 84(3), 384-399.

Pesaran, M. H., \& Shin, Y. (1998). Generalized impulse response analysis in linear multivariate models. Economics Letters, 58(1), 17-29.

Salisu, A. A., Oyewole, O. J., \& Fasanya, I. O. (2018). Modelling return and volatility spillovers in global foreign exchange markets. Journal of Information and Optimization Sciences, 39(7), 1417-1448.

Sensoy, A., \& Sobaci, C. (2014). Effects of volatility shocks on the dynamic linkages between exchange rate, interest rate and the stock market: The case of Turkey. Economic Modelling, 43, 448457.

Sobti, N. (2018). Domestic intermarket linkages: measuring dynamic return and volatility connectedness among Indian financial markets. Decision, 45(4), 325-344.

Yilmaz, K. (2010). Return and volatility spillovers among the East Asian equity markets. Journal of Asian Economics, 21(3), 304-313. 